\title{
Feasibility of using resin-jacketed piezo sensors for monitoring of concrete strength using electro-mechanical impedance technique
}

\author{
Naveet Kaur ${ }^{1, *}$ and Prateek Negi ${ }^{2}$ \\ ${ }^{1}$ Bridge Engineering and Structures Division, CSIR-Central Road Research Institute, Mathura Road, New Delhi 110025 , India \\ ${ }^{2}$ Civil Engineering Department, Govind Ballabh Pant Institute of Engineering and Technology, Ghurdauri, Pauri, Uttarakhand 246 194, India
}

The present study is on the feasibility of the effectiveness of the embedded resin-jacketed piezo (RJP) sensor for monitoring concrete strength using electromechanical impedance (EMI) technique. In this study, first resonant peak frequency in the EMI signature is preferred over other quantitative indices, including root-mean-square-deviation (RMSD) and equivalent stiffness parameter as they are based on frequency ranges chosen by a particular user's judgement. The piezo sensors used are lead zirconate titanate (PZT) based thick $(1 \mathrm{~mm})$, circular patches of diameter $10 \mathrm{~mm}$ coated with epoxy resin. The protective resin coating imparts robustness to the sensor against the rough conditions during concrete casting. The ease in fabrication and utilization of the proposed embedded configuration of the RJP sensor renders it as an appropriate choice for use in real-life site conditions. Based upon the peak resonant frequency, RMSD and equivalent stiffness parameter determined using EMI signature, we conclude that it can successfully monitor concrete strength up to first 28 days.

Keywords: Concrete hydration, compressive strength, electro-mechanical impedance, epoxy resin, piezoelectric transducers.

CAREFUL monitoring of any manufacturing or building process keeps a check on the quality of its final product. This helps in improving the service life of the product and prevents its untimely failure. In a similar context, engineers and researchers are always concerned about proper monitoring of civil structures while construction, as any negligence may incur a higher construction cost and the lives of many innocent people. In modern times, concrete is a vital material being used extensively in most of civil construction work. The industry has developed many additives and admixtures to modify the properties of concrete according to the site requirements. The Indian Standard code IS 456:2000 (ref. 1), mentions that ordinary Portland cement (OPC) concrete member should be left for a minimum of seven days for regular curing and 10 days in dry and hot weather conditions.

*For correspondence. (e-mail: nkaur.crri@nic.in)
However, the curing time increases to 10 and 14 days respectively, when blended cement and mineral admixtures are used. Due to time constraints in construction, builders do not follow this strictly and prefer to use additives like accelerators which reduce the curing time and attain the desired strength earlier than the codified time.

In conventional practices, concrete cubes are cast separately from the same concrete batch which is to be used in the construction and are later tested for developed strength. This method increases the possibility of error in determining in situ concrete strength as the curing conditions are different for cubes and the structure. Engineers also perform destructive testing in which concrete cores are bored out from the final structure and are tested for compressive strength. This is one of the most reliable methods to estimate compressive strength ${ }^{2-4}$. However, the method is destructive and damages concrete integrity and might affect the reinforcement as well. In another destructive test, known as pull off test, a metal disk prefixed to concrete is pulled out using tensile force. This force is related to the compressive strength of the concrete under observation and is preferable to detect the early strength issues of concrete ${ }^{5}$. Rebound hammer test is the most common non-destructive test for determining the strength of a concrete member. It works on measuring the surface hardness of concrete and determining the strength using resistance correlation curves. According to Malhotra $^{6}$, the results of rebound hammer test should be viewed in addition to destructive testing as they can be largely influenced by the hardness of surface aggregates, humidity and inclination of the hammer. The maturity method (ASTM C 1074), which is another non-destructive test, also has some limitations - it is sensitive to the site temperature conditions, which limits its use in practical construction projects. In another non-destructive ultrasonic pulse velocity (UPV) test, the velocity of a wave propagated through an elastic medium is recorded as a function of its elastic properties and material density. Grullón et $a l .{ }^{7}$ inferred that the inaccuracies of the UPV test result in wrong determination of strength of concrete, as the method is prone to experimental errors. Machado et al. ${ }^{3}$ found the UPV test to be least accurate for determining concrete resistance when compared to rebound hammer and penetration 
resistance tests. The above discussion shows that no nondestructive or destructive test is a complete tool to monitor the in situ strength of concrete structures. It is always advisable to use them as a combination of more than one technique for confident monitoring ${ }^{5}$. Further, researchers had highlighted the inability of using surface-bonded PZT sensors as a direct indicator of strength gain due to difference in their bonding conditions ${ }^{8,9}$.

The electro-mechanical impedance (EMI) technique has been proved to be practicable for monitoring early damages in the civil structures. Subsequently, the technique can also be used to monitor corrosion in the rebar ${ }^{10}$. It is based on acquiring impedance signatures from the host structure to be monitored as a variation of conductance of small piezo sensors over a frequency range, generally $50-400 \mathrm{kHz}$ (refs 11,12 ). The occurrence of any damage which makes the structure different from its pristine state is reflected clearly as a variation in its previous conductance signature. This variation can be reported as a change in the first resonance frequency or change in the conductance value of the peak. Also, the entire variation in the signatures can be quantified by calculating the root mean square deviation (RMSD) percentage between them as given by the eq. (1)

$$
\operatorname{RMSD}(\%)=\sqrt{\frac{\sum_{i=1}^{N}\left(G_{i}^{1}-G_{i}^{0}\right)^{2}}{\left(G_{i}^{0}\right)^{2}}} \times 100
$$

where $G_{i}^{0}$ is the baseline conductance value at the $N$ th frequency and $G_{i}^{1}$ the post-damage conductance at the same frequency point. Here, $i$ is the $N$ th frequency. Researchers in the past have worked on the feasibility of monitoring concrete hydration using the EMI technique. Shin et al. ${ }^{14}$ used surface-bonded square PZT patches to monitor increase in the strength of concrete, and found a change in conductance signatures as a reflection of a change in its mechanical impedance. They also observed a rightward and downward shift in the first resonance peak of PZT patches with increase in hydration time. Shin and $\mathrm{Oh}^{15}$ reported this technique to be sensitive towards change in strength gain of concrete. Annamdas et $a l .{ }^{16}$ double-protected the PZT patches with steel wire mesh and cement paste for safely embedding them in concrete while monitoring hydration. Wang and $\mathrm{Zhu}^{17}$ embedded a square PZT patch of $8 \times 8 \times 0.3 \mathrm{~mm}$ covered with asphalt lacquer as a waterproof coating in concrete cubes to monitor concrete hydration. They correlated RMSD variation and mean-absolute-percentage-deviation (MAPD) indexes with cube strength and developed exponential correlations between them. In total, they tested 42 cubes and reported the inability of the developed correlations to be used for other mixes. Annamdas and Yang ${ }^{18}$ monitored the temporary structure for soil excavation carried out for a mass road transport station in Singapore using a PZT-based EMI technique.
Azhari and $\mathrm{Loh}^{19}$ obtained promising results while evaluating the use of a driven piezoelectric scour sensing rod to determine scour depths using the inverse relation between natural frequency and exposed length of the rod. Some researchers had also established the use of polyvinylidene fluoride (PVDF) wireless smart sensor as a dynamic strain gauge for monitoring the structures ${ }^{20}$. Negi et al. ${ }^{21}$ studied the effectiveness of PZT patches in monitoring concrete hydration in three different orientations on a full-scale reinforced concrete beam. They reported a similar rightward and downward shift in the first resonance peak, and found $1-200 \mathrm{kHz}$ range to be most effective for monitoring strength gain. Recently, Negi et $a{ }^{22}$ have successfully utilized the proposed resinjacketed piezo (RJP) configuration for the health monitoring of reinforced concrete structures under impact.

The literature shows the limitations of surface-bonded PZT patches used for concrete hydration monitoring in real-life site conditions due to harsh environmental factors. Some researchers explored the possibility of embedded PZT configurations for hydration monitoring. However, the configuration was either complex to fabricate $^{16}$ or they used a thin square PZT patch which does not produce a distinct first resonant peak in the EMI signature $^{17}$. The first resonant peak frequency in the EMI signature is preferred over other quantitative indices, including RMSD and equivalent stiffness parameter, because they are determined based on a frequency range chosen by a particular user's judgement. Thus, the former is preferred in order to standardize data interpretation leading to its enhanced acceptance in the construction industry. The technicalities in their fabrication and installation are too high to provide similar results even for the same type of sensors. In the present study, a solution is provided to address these issues by developing a novel type of embedded configuration for the piezo sensor. In this study of concrete hydration monitoring, a circular thick $(1 \mathrm{~mm})$ PZT patch of diameter $10 \mathrm{~mm}$ with a thin layer of resin cover, i.e. RJP sensor has been used, as it shows sharp resonant peak frequency even in bonded condition. The patches used in this study are approximately four times thicker than the standard PZT patch used for the EMI technique, ensuring higher stiffness to withstand the rough casting conditions. It is further highlighted that the ease in fabrication and utilization of the proposed embedded configuration of the RJP sensor adds to the novelty of the work and renders it as an appropriate choice for use in the real-life site conditions. Thus, the novelty of this study is that it explores the circular piezo for monitoring concrete hydration, as circular shape renders a sharp distinguishable peak for the most prominent frequency in the conductance plot. A similar configuration has been used by the present authors for the health monitoring of reinforced concrete structures under impact. In this study, RJP sensors were embedded inside the concrete cubes, and the peak 


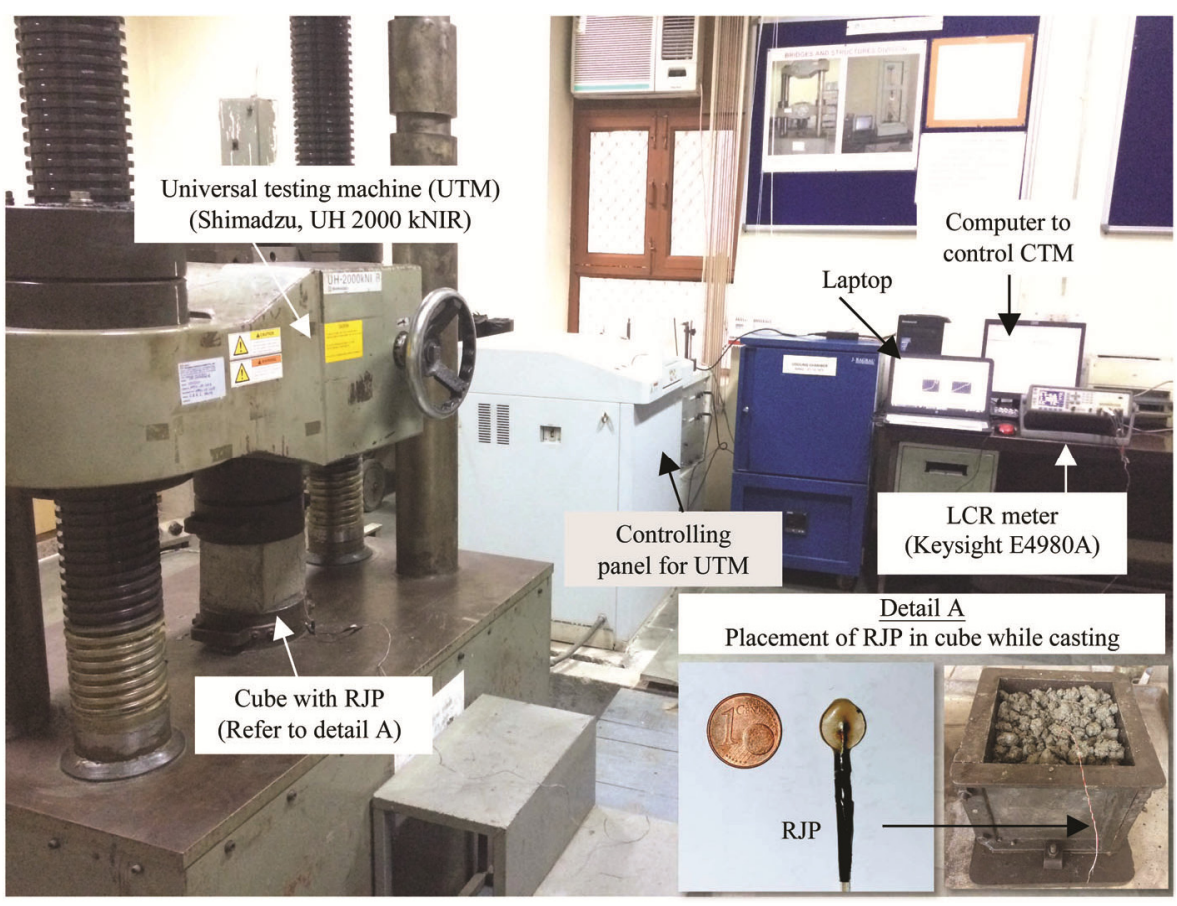

Figure 1. Complete experimental set-up.

frequency, RMSD and equivalent stiffness derived from the conductance plot of the piezo were analysed to establish its feasibility to monitor concrete strength from the day of casting until 28 days. Further, the reduction in concrete strength during different stages of compressive test on the cubes was also monitored using RJP sensors. The sensor was extracted from the cube after compression test to check its robustness and reusability.

\section{Hydration monitoring of concrete using RJP sensor}

The complete experimentation consisted of two stages. The first stage covered the fabrication of the RJP transducer and its instrumentation in the concrete cube. The second stage consisted of acquiring EMI signatures at specified intervals for monitoring the hydration of concrete. In this study, a circular PZT patch of diameter $10 \mathrm{~mm}$ and thickness $1 \mathrm{~mm}$ was used to fabricate the RJP sensor. In order to protect the soldered joints, the PZT patch was dipped in a two-part epoxy adhesive ${ }^{23}$ (Figure 1). This provided the complete assembly a protective layer against harsh conditions during casting. A total of four cubes of M40-grade were casted, of which three were instrumented with a single RJP sensor at their centroid (Figure 1) and the fourth one was a dummy cube (without RJP) casted to get an estimate of the actual concrete strength of the mix after 28 days. The constituents of mix proportion used were cement: $420 \mathrm{~kg} / \mathrm{m}^{3}$, water: $168 \mathrm{~kg} / \mathrm{m}^{3}$, coarse aggregate: $1188 \mathrm{~kg} / \mathrm{m}^{3}$ and fine aggregate: $696 \mathrm{~kg} / \mathrm{m}^{3}$.
Figure 1 shows the complete experimental set-up. The hydration of concrete was done from the day of casting till day 28 by acquiring the EMI signature of the embedded RJP. The data acquisition system used for acquiring EMI signatures of the RJP consisted of an LCR meter (Keysight E4980A) and a laptop. The conductance signatures were recorded for the RJP in the frequency range $20-1000 \mathrm{kHz}$. A universal testing machine (UTM) (Shimadzu, UH $2000 \mathrm{kNIR}$ ) was used for the compression testing of concrete cubes on day 28. Figure 2 shows the conductance signature of free RJP (before embedding) and embedded RJP for days 0 to 28 . The zoomed plot of the first natural frequency peak in the frequency range $150-250 \mathrm{kHz}$ is also shown. The exact overlap for the multiple (two) conductance readings for free RJP ensures its repeatability. Day 0 denotes the day of casting, and Figure 2 shows the conductance signatures till day 28 of casting. The time mentioned in the legend denotes the time of acquiring data on that particular day. Readings were acquired hourly during the initial hydration period, and then later the interval of acquiring the conductance signature increased. The conductance signatures for the important days are shown in the plot for clarity. A downward and rightward shift in the peak for the first resonant frequency was observed in the conductance signature with increasing number of days after casting. During the initial hours on the day of casting (day 0), when the hydration of concrete takes place, a prominent increase in the overall conductance signature (except the peak conductance value) in the whole frequency range was observed. This was due to the presence of considerable 


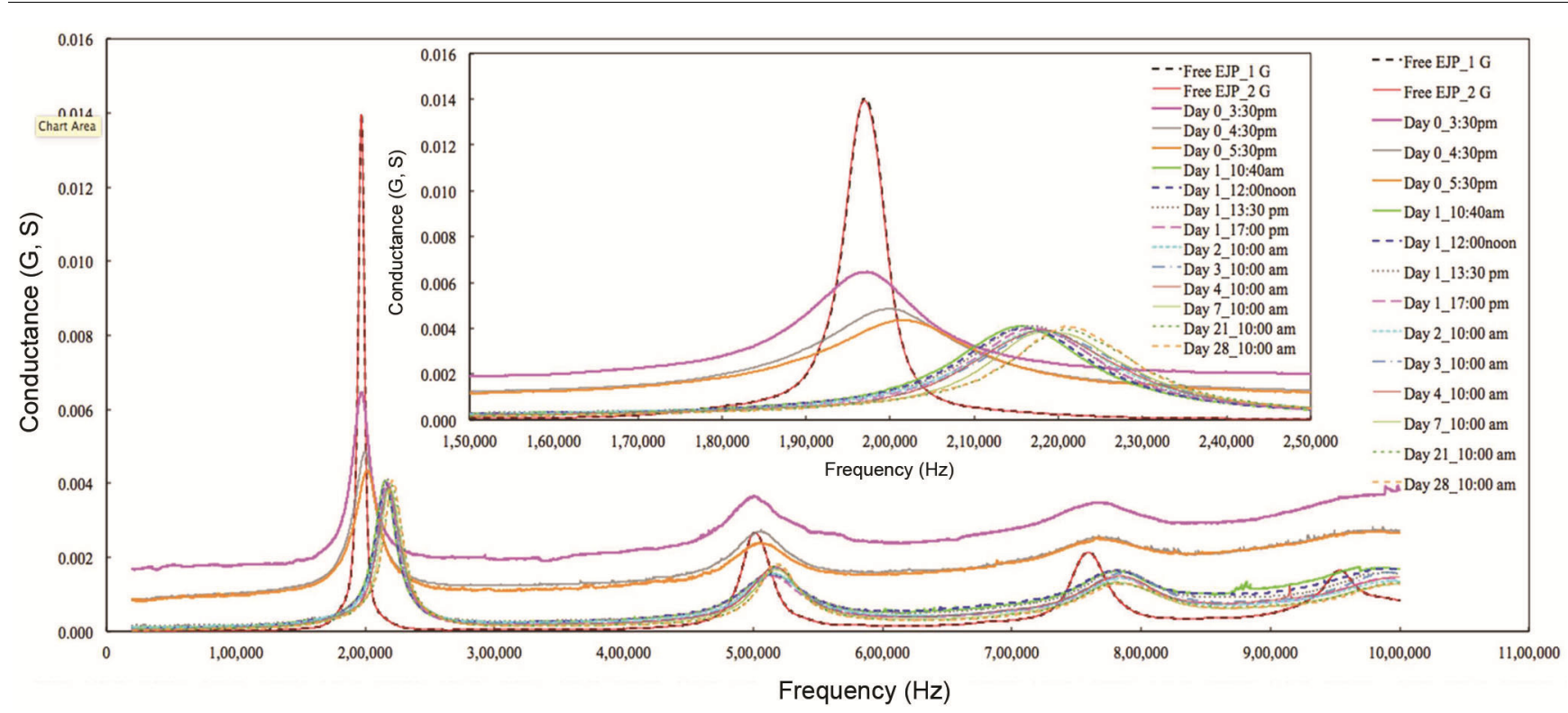

Figure 2. Conductance signature of free resin-jacketed piezo (RJP) and embedded RJP sensor in cube 1 for days 0 to 28 of casting cube with a zoomed plot of first natural frequency peak.

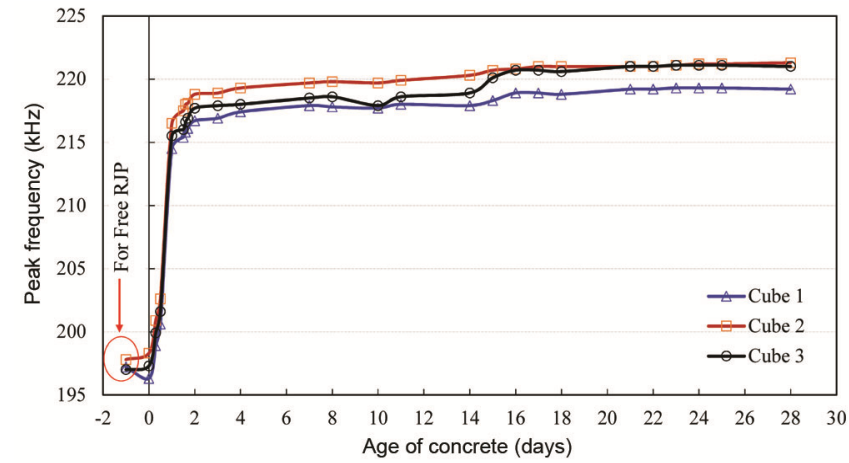

Figure 3. Variation of the first natural frequency with increasing age of cube.

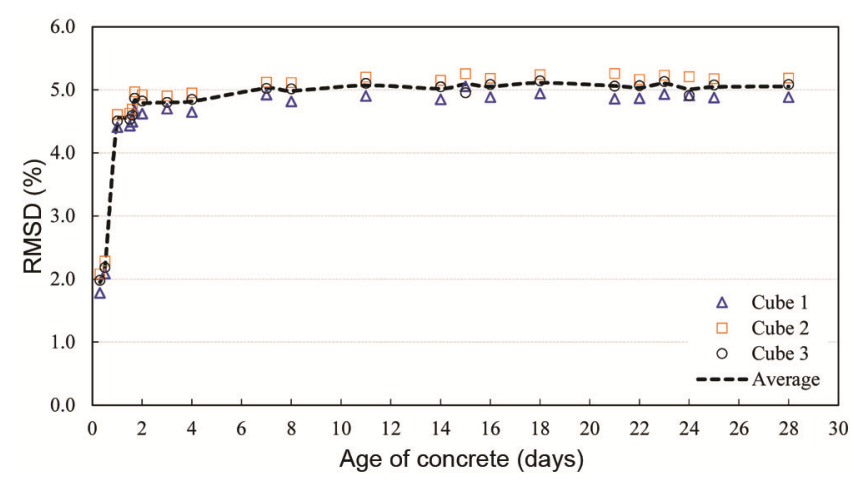

Figure 4. Variation of root mean square deviation (RMSD) with increasing age of cube by taking day 0 as the baseline signature.

amount of water during the initial hours ${ }^{21}$. A drastic reduction in peak conductance value during the initial hours followed by gradual reduction after day 1 of casting was also observed. This can be attributed to the com- bined effect of hydration (occurring during initial hours) and increase in the Young's modulus (thus strength) of concrete with time. It also caused increase in peak frequency (except during the initial $2 \mathrm{~h}$ ) with increasing number of days after casting. The widening of the plots in the frequency range $150-250 \mathrm{kHz}$ depicts the increase in damping of the system. Figure 3 shows the variation of first natural frequency with increasing age of the cube. A sharp increase in the first natural frequency was observed between day 0 and day 2 . Day 2 onwards, the frequencies increased slightly.

Figure 4 is a plot of RMSD calculated using eq. (1) by taking day 0 as the baseline signature. The RMSD showed similar observations as the slope increased sharply till day 1 . Further, sensitivity towards increasing concrete strength reduced drastically till day 8 and almost became negligible from day 8 to day 28 . Here, it needs to be emphasized that the RMSD is a user-dependent quantitative index, as one can choose any frequency range for determining the same. Therefore, it is concluded that peak resonant frequency of the conductance plot for embedded RJP is a better quantitative index compared to RMSD, because the former exhibits slightly improved sensitivity and is a user-independent quantitative index.

\section{Equivalent strength parameters}

One more method was employed to further establish the feasibility of using embedded RJP sensors for concrete strength monitoring. This is an empirical method developed by Bhalla and $\mathrm{Soh}^{24}$ for determining the equivalent structural parameters (ESPs), namely equivalent stiffness $(k)$, mass $(m)$ and damping $(c)$ derived using impedance 

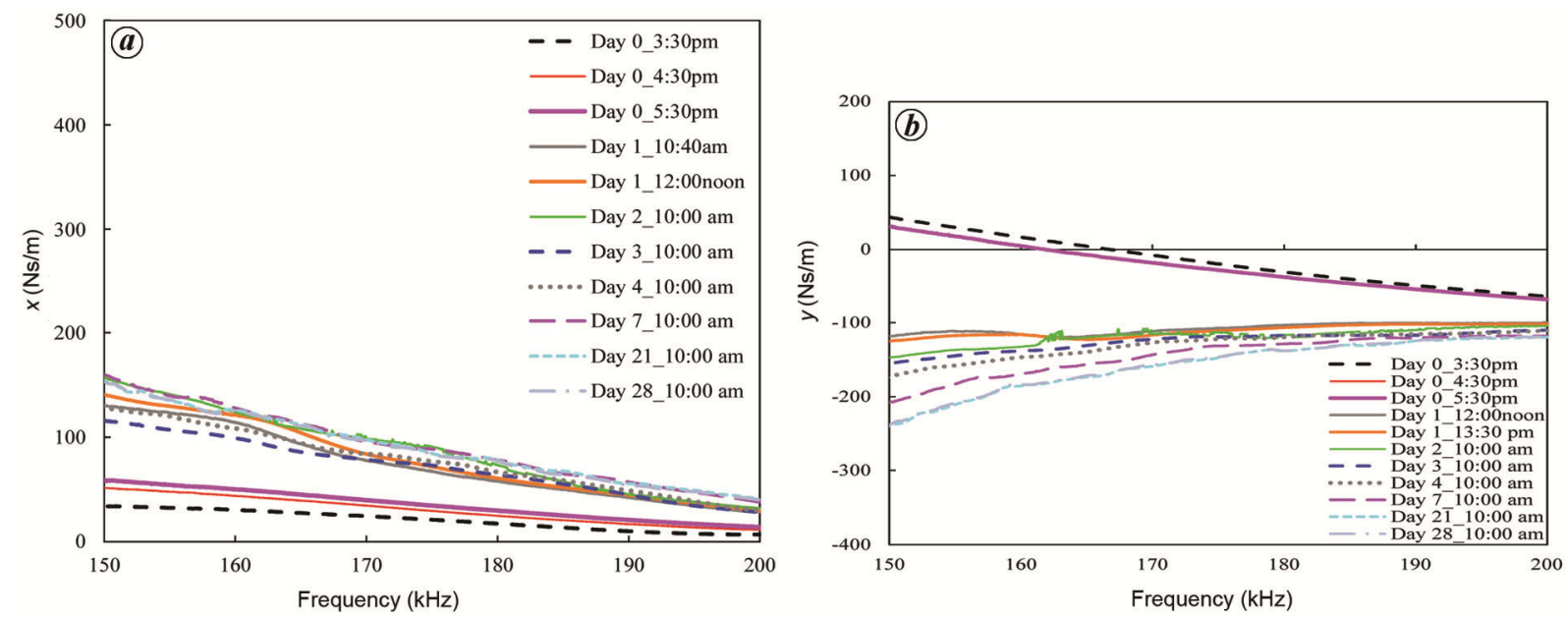

Figure 5. Variation of structural impedance components $(\boldsymbol{a})$ equivalent $x$ and $(\boldsymbol{b})$ equivalent $y$ with increasing age of concrete cube.
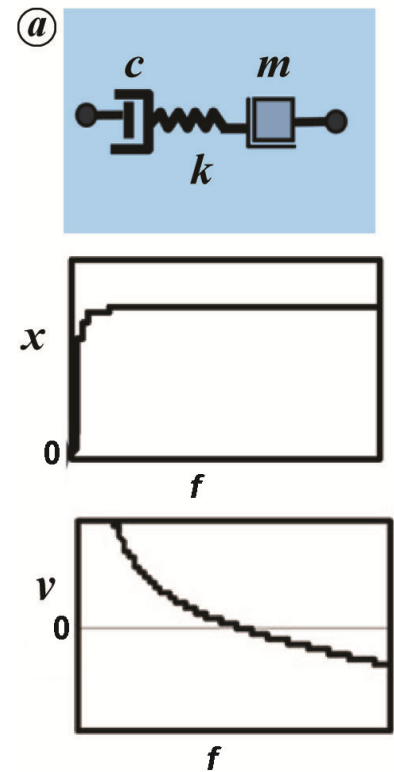

(b)
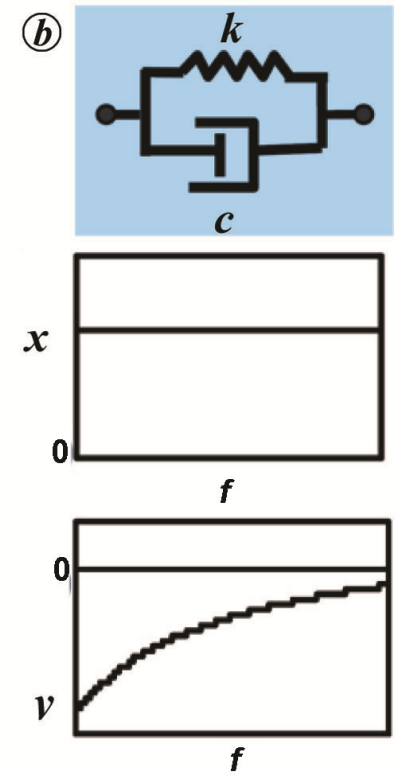

Figure 6. Pictorial representation of two different mechanical systems of $m-c-k$ with their typical variation of $x$ versus $f$ and $y$ versus $f$ for $(\boldsymbol{a})$ series mechanical system and $(\boldsymbol{b})$ parallel mechanical system ${ }^{24}$.

signature of a PZT. It is based on extracting structural impedance $\left(Z_{s, \text { eff }}\right)$ components, i.e. $x$ and $y$ at every $\omega$ $(=2 \pi f)$ the angular frequency $(\mathrm{rad} / \mathrm{s})$ at measuring frequency $(f)$ for square PZT patches. The same method has been used in the present study by considering an equivalent square PZT patch of sides equal to the diameter of the circular PZT actually used in the experimentation. Figure 5 shows typical $x$ and $y$ plots with increasing age of concrete for cube 1 . A careful analysis of the plots of $x$ and $y$ in the frequency range $140-200 \mathrm{kHz}$ revealed that the equivalent mechanical system consisted of a dashpot, a spring and a mass connected in series (Figure $6 a$ ) for day 0 , and a dashpot and a spring in parallel (Figure $6 b$ ), from day 1 onwards. Figure 6 also shows the typical variation of $x$ and $y$ for the identified series $m-c-k$ system and parallel $c-k$ system. Since concrete was transitioning from green state (during day 0) to hardened state (day 1 onwards), the $x$ versus $f$ and $y$ versus $f$ plots for day 0 exhibit a different model from that for day 1 onwards. Thus, two models are dealt with differently for determining the ESP values.

For day 0 , the experimental values of $x$ and $y$ were used to calculate ESP, i.e. $m, c, k$ using eqs (2)-(4) for the series $m-c-k$ system $^{25}$.

$$
\begin{aligned}
& c_{i}=\frac{x_{i}^{2}+y_{i}^{2}}{x_{i}}, \\
& m_{i}=\frac{c_{i} y_{i}\left(\omega_{i}^{2}-\omega_{0}^{2}\right)}{\left(x_{i}-c_{i}\right) \omega_{i} \omega_{0}^{2}}, \\
& k_{i}=\frac{c_{i} y_{i}\left(\omega_{i}^{2}-\omega_{0}^{2}\right)}{\left(x_{i}-c_{i}\right) \omega_{i}} .
\end{aligned}
$$

Here, $\omega_{0}$ is the angular frequency when $y=0$ and $x_{i}$ and $y_{i}$ denote the experimental structural impedance components corresponding to the $i$ th angular frequency $\left(\omega_{i}\right)$, where $i$ is $1,2,3 \ldots n$. Using eqs (2)-(4), ESP values were derived at each measurement point within the frequency range to obtain average values. The values of equivalent $x$ and $y$ for each frequency were calculated using the average values of the parameters $m, c$ and $k$ as

$$
x=\frac{1 / c}{1 / c^{2}+(\omega / k-1 / \omega m)^{2}} ; y=\frac{-(\omega / k-1 / \omega m)}{1 / c^{2}+(\omega / k-1 / \omega m)^{2}} .
$$

For day 1 onwards, when the system was identified as parallel spring-damper $(k-c)$ combination, the values of equivalent $x^{\prime}$ and $y^{\prime}$ are given by

$$
x^{\prime}=c \text { and } y^{\prime}=-\frac{k}{\omega} .
$$



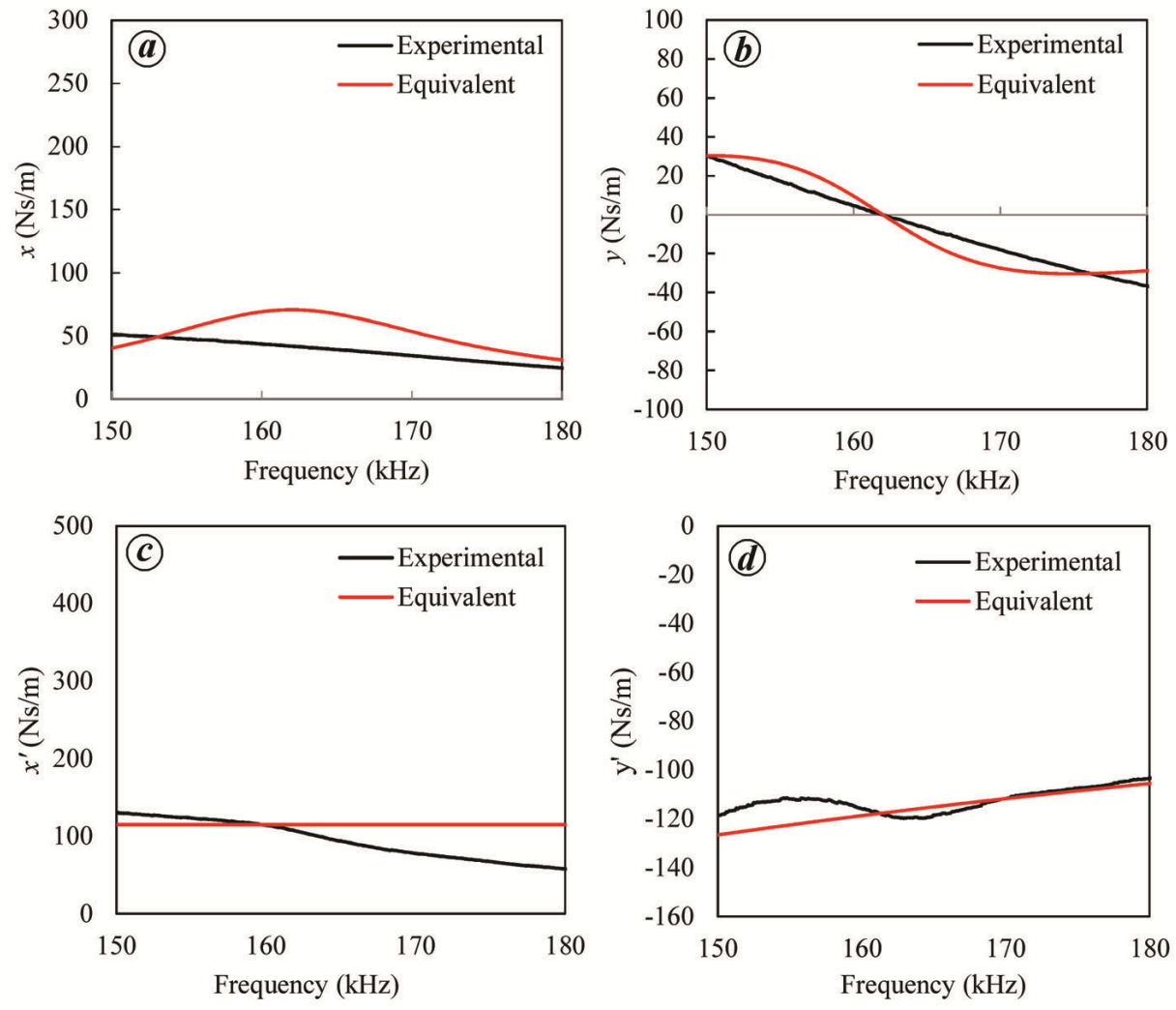

Figure 7. Comparison of experimental and equivalent plots of real and imaginary parts of structura impedance. $\boldsymbol{a}, x$ versus $f$ for day $0 ; \boldsymbol{b}, y$ versus $f$ for day $0 ; \boldsymbol{c}, x^{\prime}$ versus $f$ for day $1 ; \boldsymbol{d}, y^{\prime}$ versus $f$ for day 1 .

The average values of the $m, c$ and $k$ for a typical case when the readings were acquired on day 0 were obtained as $m=1.09 \times 10^{-5} \mathrm{~kg}, k=1.17 \times 10^{7} \mathrm{~N} / \mathrm{m}$ and $c=34.65 \mathrm{Ns} / \mathrm{m}$. For a typical case on day 1 , the average ESP values were worked out as: $c=115 \mathrm{Ns} / \mathrm{m}$ and $k=1.19 \times 10^{5} \mathrm{~N} / \mathrm{m}$ using eq. (6). Figure 7 shows a typical comparison of experimental and equivalent $x$ and $y$ values obtained for these typical cases with reasonable agreement between them.

The gain in strength of concrete is indicated by the increase in structural stiffness. Hence, the equivalent structural parameter $k$ derived above is of prime importance. Figure 8 shows the variation of equivalent stiffness in cube 1 for increasing age of concrete. It can be observed from the figure that the equivalent stiffness of the system is considerably high on day 0 in comparison to the values for day 1 onwards. As concrete was in green state during day 0 , the RJP sensor behaved similar to the free PZT sensor, which is also established from the conductance signature shown in Figure 2. Hence, the equivalent stiffness derived for day 0 (Figure $8 a$ ) is not the true representation of structural stiffness, as it might be indicating the stiffness of RJP which was not restrained completely. From Figure $8 b$, an increase in the equivalent stiffness is observed with increase in the age of concrete, which establishes the possibility of monitoring concrete hydration using equivalent stiffness parameter derived from the conductance signature of the RJP sensor.

From the above study, it can be concluded that both the peak resonant frequency and RMSD are better quantitative indices for day 0 in comparison to equivalent stiffness parameter. However, both exhibit reduced sensitivity after the first day of casting. Whereas, the equivalent stiffness becomes much more sensitive to concrete hydration/strength gain after the first day of casting. Thus, the latter should be preferred over RMSD for hydration/ strength gain in concrete after the first day of casting. However, it again needs to be highlighted here that the equivalent stiffness method is highly dependent on user judgement for selecting the appropriate frequency range for analysis. Therefore, though it is more sensitive than peak resonant frequency after the first day of casting, the latter shall be given preference in order to standardize data interpretation leading to its enhanced acceptance in the construction industry.

Based on the peak frequency, RMSD and equivalent stiffness derived from the conductance plot of the piezo, it can be concluded that the RJP sensor could successfully monitor increasing concrete strength till 28 days after casting. Therefore it can be effectively used in robust site conditions for concrete strength gain monitoring. With further advancement in the present study, calibration models can be developed based on 'peak resonant 

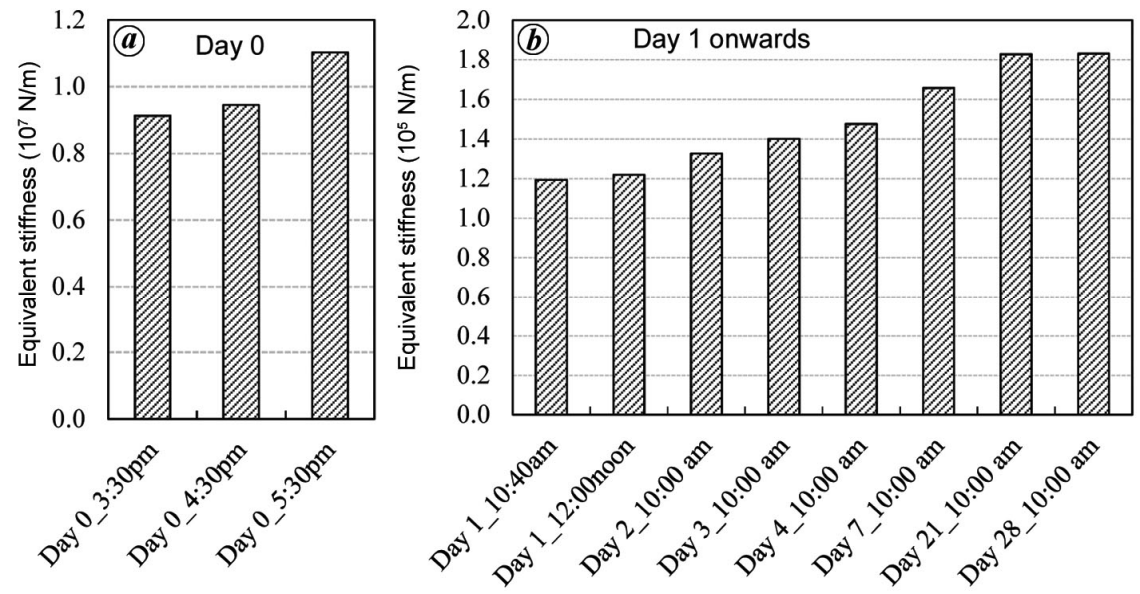

Figure 8. Variation of equivalent stiffness (a) day 0 and (b) day 1 onwards.

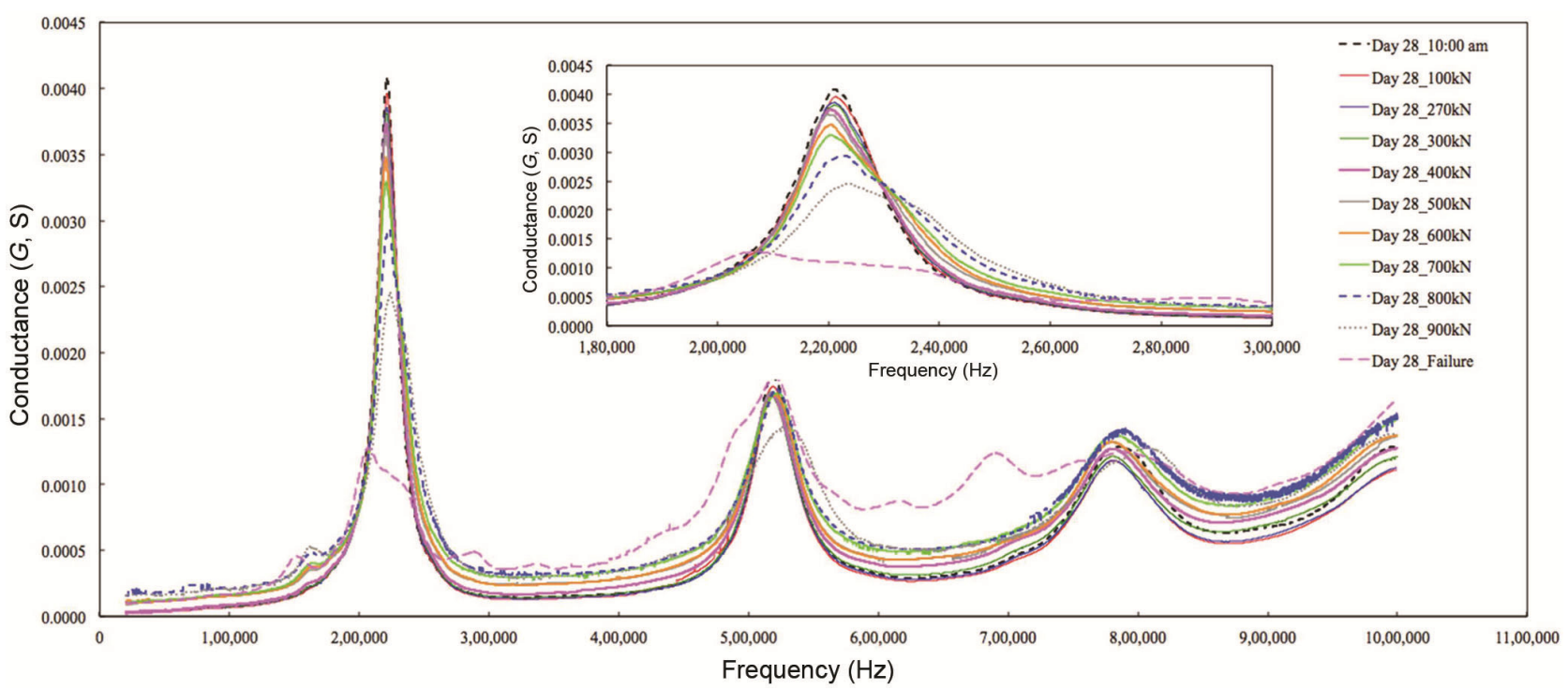

Figure 9. Conductance signature on day 28 with increasing compressive load.

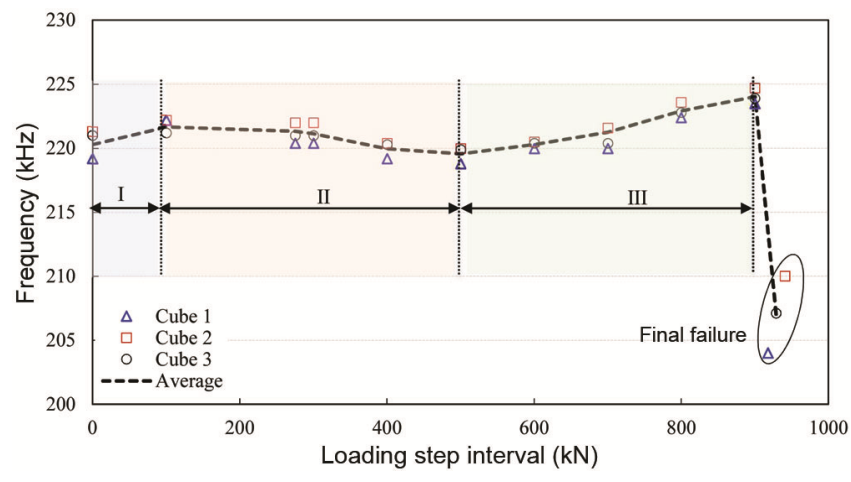

Figure 10. Variation of the first natural frequency with increasing compressive load on day 28.

frequency in the EMI signature of RJP sensors' and 'concrete strength' for sufficiently large number of cubes. Thus, this technique can act as a non-destructive tool (in addition to the compressive test of the cubes) for CURRENT SCIENCE, VOL. 119, NO. 8, 25 OCTOBER 2020 estimating the instantaneous in situ concrete strength. This can further help in decision making regarding the appropriate time for form-work removal in the site conditions.

\section{Monitoring reduced concrete strength using RJP sensor}

The feasibility of using embedded RJP sensors for monitoring concrete strength was also tested for checking the reduction in strength during compression testing of cubes. A progressive compression test was done for the concrete cube with RJP sensor by increasing the compressive load at fixed intervals in a controlled fashion on day 28. The ultimate load for concrete was determined by crushing the cube without RJP sensor. The maximum loadcarrying capacity of the uninstrumented concrete cube was found to be $902.2 \mathrm{kN}\left(40.1 \mathrm{~N} / \mathrm{mm}^{2}\right)$, experimentally. 


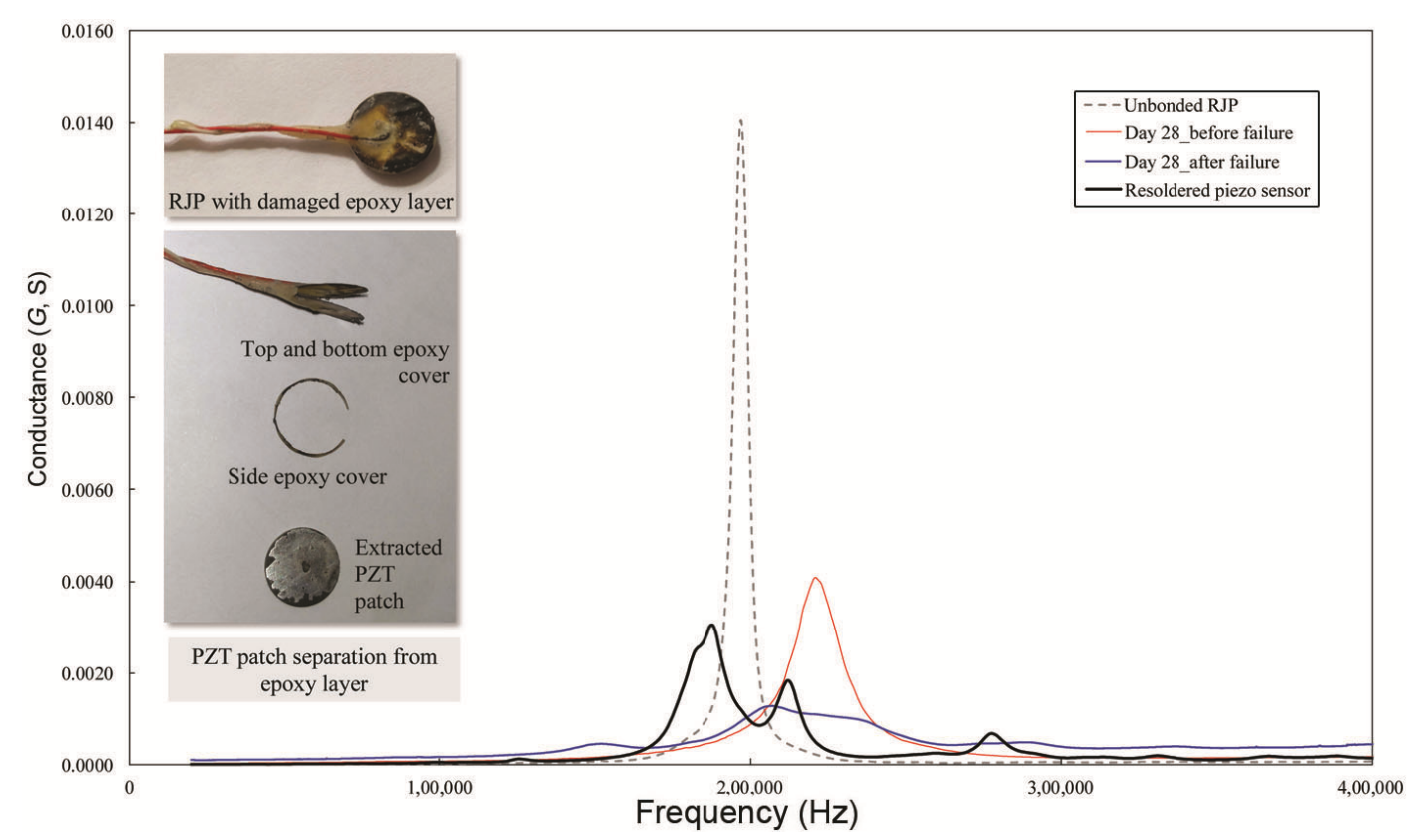

Figure 11. Conductance signature of extracted and resoldered piezo sensor in comparison with free RJP and embedded RJP signature on day 28.

After obtaining an estimate of the ultimate compressive load carrying capacity of the cube, the EMI signatures of the RJP sensors were acquired at a load step interval of $100 \mathrm{kN}$ for sufficient sets of readings. The conductance signature of the RJP sensor embedded typically in cube 1 was acquired for different load interval values on the 28th day (Figure 9). It can be observed from the first natural frequency piezo peak $(150-250 \mathrm{kHz})$ that both peak conductance value and first natural frequency both decrease with increasing applied load. This could be attributed to the reduction in stiffness of the cube with increasing compressive load. The ultimate failure load $(929.69 \mathrm{kN})$ is prominently captured by the RJP sensor. Figure 10 shows the variation of the first natural frequency of the RJP sensor embedded in three cubes with increasing compressive load. During stage I, the pores in the concrete became compressed, thereby, increasing the overall density and stiffness of the material. This resulted in an increase in the first natural frequency value. In the later stage of loading, concrete started developing micro and macro fractures, resulting in reduction of the stiffness value. This reduction was observed up to a loading of $500 \mathrm{kN}$ (approx. $60 \%$ of the maximum value). Later in stage III, the concrete cube started developing major fractures resulting in separation of the concrete region around the sensor from the rest of the block. As the mass around the sensor reduced drastically, this reflected as a further increase in the frequency values. The sharp reduction in frequency at ultimate failure load depicts the clear failure condition successfully captured by the RJP sensor. Hence, it can be ascertained that any major change in the trend of frequency reflects a change in the stiffness of the concrete cube.

\section{Extraction of RJP sensor from the specimen}

In order to check the reusability and robustness of the RJP sensor, it was carefully extracted from the cube specimen. It was observed that the top and bottom epoxy layers were damaged possibly due to the ingress of moisture from the thin epoxy layer (Figure 11). The piezo sensor was carefully removed and resoldered to record the conductance signature of the extracted sensor. Figure 11 shows the conductance signature of the resoldered piezo sensor compared to the free RJP sensor and the 28 th day signature. The peak frequency for the resoldered piezo sensor was found close to the unbonded RJP, affirming its free-free condition and thus robustness and reusability.

\section{Conclusion}

This study establishes the feasibility of the RJP sensor to monitor concrete hydration and reduced concrete strength during its compressive test using the EMI technique. The first natural frequency of piezo was tracked for monitoring the concrete hydration and strength. During the initial hours on the day of casting (day 0), when the hydration of concrete was taking place, a prominent increase in the overall conductance signature (except the peak conductance value) in the whole frequency range was observed. This was due to presence of considerable amount of water during the initial hours ${ }^{21}$. The drastic reduction in peak conductance value during the initial hours followed by gradual reduction after day 1 of casting was observed. This can be attributed to the combined effect of hydration (occurring during initial hours) and increase in the 


\section{RESEARCH ARTICLES}

Young's modulus (thus strength) of concrete with time. It also caused an increase in the peak frequency (except during the initial $2 \mathrm{~h}$ ) with increase in the number of days after casting. Also, widening of the plots in the frequency range $150-250 \mathrm{kHz}$ depicts the increase in damping of the system. Sharp increase in first resonant peak frequency was observed between day 0 and day 2. Day 2 onwards, the frequency either increased slightly or was almost constant. The equivalent stiffness derived from the EMI signature of cube 1 increased with increasing age of concrete. Day 1 onwards, equivalent stiffness was found to be more sensitive to concrete hydration in comparison to RMSD. Though equivalent stiffness parameter was more sensitive than peak resonant frequency after the first day of casting, the latter shall be given preference in order to standardize data interpretation leading to its enhanced acceptance in the construction industry.

Based on the results, it is concluded that the RJP sensors can be effectively used in robust site conditions for concrete strength gain monitoring. This extended study can act as a non- destructive tool (in addition to the compressive test of cubes) for estimating the appropriate time for form-work removal in the site conditions, by estimating the instantaneous in situ concrete strength.

1. IS 456 (2000), Plain and reinforced concrete - code of practice Bureau of Indian Standards, New Delhi, 2000.

2. Bartlett, F. M. and Mac Gregor, J. G., Cores from high performance concrete beams. ACI Mater. J., 1994, 91, 567-576.

3. Machado, M. D., Shehata, L. C. D. and Shehata, I. A. E. M., Correlation curves to characterize concretes used in Rio de Janeiro by means of non destructive tests. Rev. IBRACON Mater. Estrut. RIEM, 2009, 2(2), 100-123.

4. Minkwan, J., Kyoung, S. P. and Hongseob, O., Estimation of compressive strength of high strength concrete using nondestructive technique and concrete core strength. Appl. Sci., 2017, 7,1249 .

5. PereiraI, E. and Medeiros, M. H. F., Pull off test to evaluate the compressive strength of concrete: an alternative to Brazilian standard techniques. Rev. IBRACON Estrut., 2012, Mater. 5(6).

6. Malhotra, V. M., In situ/nondestructive testing of concrete - a global review, in situ/nondestructive testing of concrete. SP-82 American Concrete Institute, Detroit, 1984, pp. 1-16.

7. Grullón, M., Barbosa, P., Medeiros, M. and Helene, P., Correlação entre resistência à compressão e ultrassom: influência da dosagem e da umidade. In: IBRACON, II - Construçõesem Concreto Trabalho CBC0101, 2004, 2, 587-596.

8. Lim, Y. K., Kwong, K. Z., Liew, Y. W. Z. and Soh, C. K., Nondestructive concrete strength evaluation using smart piezoelectric transducer - a comparative study. Smart Mater. Struct., 2016, 25(8); https://doi.org/10.1088/0964-1726/25/8/085021.

9. Tawie, R. and Lee, H. K., Piezoelectric-based non-destructive monitoring of hydration of reinforced concrete as an indicator of bond development at the steel-concrete interface. Cem. Concr. Res., 2010, 40(12), 1697-1703.

10. Talakokula, V., Bhalla, S., Bhattacharjee, B. and Gupta, A., Nondestructive assessment of rebar corrosion using piezo-transducers via equivalent structural parameters. Curr. Sci., 2015, 108(10), 1890-1900.

11. Park, S., Ahmad, S., Yun, C. B. and Roh, Y., Multiple crack detection of concrete structures using impedance-based structural health monitoring techniques. Exp. Mech., 2006, 46, 609-618; doi:10.1007/s11340-006-8734-0.

12. Park, G. and Inman, D. J., Structural health monitoring using piezoelectric impedance measurements. Philos. Trans. R. Soc. A, 2007, 365, 373-392; doi:10.1098/rsta.2006.1934.

13. Giurgiutiu, V., Reynolds, A. and Rogers, C., Experimental investigation of E/M impedance health monitoring for spot-welded structural joints. J. Intell. Mater. Syst. Struct., 1999, 10, 802-812.

14. Shin, S. W., Qureshi, A. R., Lee, J. Y. and Yun, C. B., Piezoelectric sensor based nondestructive active monitoring of strength gain in concrete. Smart Mater. Struct., 2008, 17, 55002; doi:10.1088/ 0964-1726/17/5/055002.

15. Shin, S. W. and Oh, T. K., Application of electro-mechanical impedance sensing technique for online monitoring of strength development in concrete using smart PZT patches. Constr. Build. Mater., 2009, 23, 1185-1188; doi:10.1016/j.conbuildmat.2008. 02.017 .

16. Annamdas, V. G. M., Yang, Y. and Soh, C. K., Impedance based concrete monitoring using embedded PZT sensors. Int. J. Civ. Struct. Eng., 2010, 1(3), 414-424.

17. Wang, D. and Zhu, H., Monitoring of the strength gain of concrete using embedded PZT impedance transducer. Constr. Build Mater., 2011, 25(9), 3703-3708.

18. Annamdas, V. G. M. and Yang, Y., Practical implementation of piezo-impedance sensors in monitoring of excavation support structures. Struct. Control Health Monit., 2012, 19(2), 231-245.

19. Azhari, F. and Loh, K. J., Laboratory validation of buried piezoelectric scour sensing rods. Struct. Control Health Monit, 2017, 24(9), e1969.

20. Gu, H., Zhao, Y. and Wang, M. L., A wireless smart PVDF sensor for structural health monitoring. Struct. Control Health Monit, Spec. Issue, 2005, 12(3-4), 329-343.

21. Negi, P., Chakraborty, T., Kaur, N. and Bhalla, S., Investigations on effectiveness of embedded PZT patches at varying orientations for monitoring concrete hydration using EMI technique. Constr. Build. Mater., 2018, 169, 489-498.

22. Negi, P., Chhabra, R., Kaur, N. and Bhalla, S., Health monitoring of reinforced concrete structures under impact using multiple piezobased configurations. Constr. Build. Mater., 2019, 222, 371-389.

23. Mohrana, S. and Bhalla, S., Numerical investigation of shear lag effect on PZT-structure interaction: review and application. Curr. Sci., 2012, 103(6), 685-696.

24. Bhalla, S. and Soh, C. K., Structural health monitoring by piezoimpedance transducers. II: application. J. Aerospace Eng., 2004, 17, 166-175.

25. Bhalla, S., Moharana, S., Talakokula, V. and Kaur, N., Piezoelectric materials applications in SHM, energy harvesting and biomechanics. Athena Academic \& Wiley. 2017, ch. 2, p. 33.

ACKNOWLEDGEMENTS. We thank the Department of Science and Technology, Government of India for providing funds (grant number DST/INSPIRE/04/2015/000545) to carry out this study.

Received 14 February 2020; revised accepted 1 August 2020

doi: $10.18520 / \mathrm{cs} / \mathrm{v} 119 / \mathrm{i} 8 / 1291-1299$ 